\title{
ATROPHIC GASTRITIS (AG) AND ITS CLINICAL SEQUELS AMONG ELDERLY PEOPLE IN FINLAND AND ESTONIA. A COMPARATIVE STUDY USING GASTROPANEL AND B12- VITAMIN TESTING OF THE RESIDENTS IN ASSISTED-HOUSING FACILITIES
}

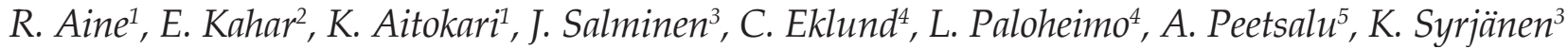

\begin{abstract}
Objective: Atrophic gastritis (AG) is associated with severe clinical sequels, including malabsorption of vitamin-B12, calcium, iron, magnesium, and zinc, with potential to develop irreversible neurological complications (e.g. dementia). To assess the prevalence of AG and its clinical sequels by serum biomarker testing and B12-vitamin measurement in elderly people in Estonia and Finland. Methods: In total, 209 residents of assisted-housing facilities (mean age 82 years) were screened by GastroPanel (Biohit Oyj, Finland) and active B12-vitamin test, the results linked with their medical history. Results: Study subjects in Tampere $(\mathrm{n}=106)$ and Tartu $(\mathrm{n}=103)$ differed in many characteristics of their medical history, including previously diagnosed B12-vitamin deficiency $(p=0.006)$. Data requested for GastroPanel testing disclosed significantly less use of PPI medication and B12-vitamin supplementation in Tartu ( $\mathrm{p}=0.0001)$. GastroPanel diagnostic profile ( 5 categories) was significantly different ( $\mathrm{p}=0.0001)$, most markedly the HP-prevalence (all cases) (52.4\%\% vs 24.5\%). AG in Finland (12.3\%) and Estonia (15.6\%) was not different (p=0.494), but manifest B12-vitamin deficiency was more common in Tartu (23.3\% vs. 3.8\%)( $\mathrm{p}=0.0001)$. Of all known complications of AG, only i) the diagnosed vitamin B12 deficiency $(\mathrm{OR}=3.5)$, and ii) diagnosed pernicious anaemia $(\mathrm{OR}=9.4)$ were significantly associated with AG. Conclusions: In Estonia, the majority (92\%) of B12-vitamin deficient cases remained undiagnosed as compared to Finland $(23.5 \%)$. To prevent irreversible complications, early diagnosis and adequate supplementation of vitamin B12 deficiency is essential. This is best done by detecting the subjects at risk (AG patients) by targeted GastroPanel screening, even years before the development of protean clinical manifestations.
\end{abstract}

Key words: Atrophic gastritis, B12-vitamin deficiency, elderly people, GastroPanel, PPi medication, malabsorption.

\section{Introduction}

Atrophic gastritis (AG) in the stomach body (corpus) leads to decreased gastric acid output and eventually acid-free stomach. The age-specific prevalence of AG increases with age, reaching $8 \%$ among people over 70 years of age, in a recent study in Finland (2). In most cases, achlorhydria had not been diagnosed previously and $13 \%$ of them used PPIs regularly $(2,3)$.

AG develops by two different mechanisms: 1) as a result of Helicobacter pylori (HP) infection, and 2) through an autoimmune mechanism $(4,5)$. In 1994, IARC declared HP-infection as carcinogenic to humans (6). The

1. IKIFIT Oy, Tampere, Finland; 2. Elli Kahar Ltd, Tartu, Estonia; 3. Department of Clinical Research, Biohit Oyj, Helsinki, Finland; 4Department of Research and Development, Biohit Oyj, Helsinki, Finland; 5. Department of Surgery, Faculty of Medicine, University of Tartu, Estonia.

Corresponding Author: Lea Paloheimo, PhD; Department of Clinical Research, Biohit Oyj, Laippatie 1, FIN-00880 Helsinki, Finland. Tel: 358-40-7523050; e-mail: lea.paloheimo@biohit.fi

Received May 17, 2016

Accepted for publication May 24, 2016 relative risk of gastric cancer (GC) increases in parallel with increasing severity and extent of AG (7-12). In addition, AG is associated with a wide variety of clinical sequels, many of which causing significant comorbidity particularly among elderly people $(13,14)$. As the output of gastric acid is reduced, absorption of iron, calcium, zinc and some drugs is impaired $(13,14)$. Iron deficiency anaemia and osteoporosis are the clinically most relevant consequences of iron and calcium malabsorption, respectively (13).

Of all AG-associated complications, however, the best know is pernicious anaemia, caused by B12vitamin deficiency due to impaired absorption $(13,15)$. This condition is a growing health concern world-wide, particularly in aged populations, leading to protean clinical manifestations: peripheral neuropathy, depression and dementia, sometimes very quickly. Elevated concentrations of homocysteine (Hcy) can interfere with folic acid metabolism (16), increasing the risk of dementia, vascular calcification and cardiovascular obstructions. 
Neural damage is often irreversible if the deficiency is not treated on time (13-16).

Early detection of AG and vitamin-B12 deficiency are prerequisites for effective prevention of these potentially harmful complications (13-16). This necessitates diagnostic tests suitable for large-scale screening of the subjects at risk. Such a test was developed some years ago, known as GastroPanel® (Biohit Oyj Helsinki, Finland) (17-20). This ELISA-based test measures the plasma levels of four stomach-specific biomarkers: pepsinogen I (PGI) and II (PGII), gastrin-17 (G17), and HP IgG antibodies (17-20). During the past several years, GastroPanel test has been extensively validated for diagnosis of symptomatic (dyspeptic) patients and in screening of GC risk groups (21-28). Equally important are systematic studies investigating vitamin-B12 deficiency and its sequels (29). The lack of such data will even accentuate, if the risk of Alzheimer's disease (AD) is conclusively linked with vitamin-B12 deficiency (30).

The present study was designed to explore the role of AG as the cause of B12-vitamin deficiency and other sequels among elderly Finnish population. The same protocol was reproduced in Estonia, to provide a wider regional perspective. The study seeks answers to two pivotal hypotheses: i) the prevalence of undiagnosed AG and B12-vitamin deficiency in senior citizens living in assisted-housing facilities is substantial, and ii) a significant portion of degenerative diseases in old age can be attributed to undiagnosed deficiency of B12-vitamin and trace elements, linked with AG and acid-free stomach $(13-16,30)$.

\section{Material and methods}

\section{Study Design}

This comparative study is targeted to elderly residents of assisted-housing facilities in two Baltic region countries (Finland and Estonia). The study is an openlabel observational study, investigating the frequency of manifest AG and vitamin-B12 deficiency by laboratory testing and the morbid history by medical records, with no restrictions in the subject selection.

\section{Study Subjects}

The material of the present study consists of 209 elderly people (mean age 82.0 years; range: 65-99 years) being residents in three assisted-housing facilities in Finland (Peurankallio Center, Tammenlehvä Center, and Kuusela Center, Tampere; $\mathrm{n}=106)$ and one in Estonia (Tartu Nursing Home, Tartu; $\mathrm{n}=103$ ). Both studies were run independently in Finland and Estonia, including the ethical approval: by i) the Regional Ethical Committee of Tampere University District) (10.3.2015; ETL-code R15047), and by ii) the Research Ethics Committee of the University of Tartu (Protocol nr. 249/T-10; 10.09.2015).

\section{Methods}

\section{Subject information leaflet and consent form}

All study subjects received oral and written information about the study, and were asked for their written consent to participate. Excluded were persons with impaired capacity in understanding the provided information.

\section{Clinical information and medical records}

A physician in charge at each study site provided the pertinent clinical information on each study subject's morbid history based on their medical records. The essential information included the list of diagnoses as well as the regular daily medications. Permission for the use of this information was requested from each subject at the time of their consenting to participate.

\section{Laboratory analyses}

Blood sampling of all study participants was completed by one trained laboratory nurse during one weekend. All samples were properly stored and transported to the service laboratory of Biohit Oyj (Helsinki) for analyses by: i) GastroPanel test, and ii) Biohit active B12 vitamin (HoloTC) test.

GastroPanel test and its interpretation: Each GastroPanel sample is accompanied by a referral form including specific questions relevant to the interpretation of the test $(17,18,29)$. GastroPanel is an automated ELISA test measuring the plasma levels of 4 biomarkers: 1 ) pepsinogen I, 2) pepsinogen II, 3) gastrin-17, and 4) HP IgG antibodies (17, 18, 19, 20). Results are interpreted using the GastroSoft software, classifying the results into one of the five diagnostic categories: 1) normal stomach, 2) superficial (HP) gastritis, 3) atrophic gastritis of the antrum (AGA), 4) atrophic gastritis of the corpus (AGC), or 5) atrophic pangastritis (AG of the antrum and corpus) (AGP). The usual GastroPanel cut-off values were used as the criteria of AG: i) AG of corpus (PGI $<30 \mu \mathrm{g} / 1$ and/ or PGI/PGII ratio $<3.0)$, ii) AG of the antrum (G-17 $<1.0$ $\mathrm{pmol} / \mathrm{l}$ ), and iii) atrophic pangastritis; G17 $<1.0 \mathrm{pmol} / \mathrm{l}$, and PGI $<30 \mu \mathrm{g} / 1$ and/or PGI/PGII ratio $<3.0)$. The cutoff for HP infection is $\geq 30$ EIU $(17,18,19,20)$.

Active B12 vitamin (HoloTC) test: Biohit Active B12 (HoloTC) ELISA test is applicable for both automated and manual systems, the former being used in our laboratory. The reference range of active B12 vitamin levels falls between 21-123 pmol/l, here graded into 3 categories for statistical purposes: 1) $<21 \mathrm{pmol} / \mathrm{l}$, severe deficiency; 2) $\geq 21-29 \mathrm{pmol} / \mathrm{l}$, deficiency, and 3) 30-123 pmol/1, normal levels. 
Table 1

Key demographic characteristics and disease history of the study subjects

\begin{tabular}{|c|c|c|c|c|c|}
\hline \multirow[t]{3}{*}{ Variable } & \multicolumn{4}{|c|}{ Study Site } & \multirow{3}{*}{$\begin{array}{c}\text { Significance } \\
\text { p-value }\end{array}$} \\
\hline & \multicolumn{2}{|c|}{ Tampere (Finland) } & \multicolumn{2}{|c|}{ Tartu (Estonia) } & \\
\hline & Number & Per Cent & Number & Per Cent & \\
\hline Number of study subjects & 106 & & 103 & & NA \\
\hline Age $(\mathrm{M} \pm \mathrm{SD})$ (years) & 84.2 & 6.0 & 79.7 & 9.2 & $\mathrm{p}=0.0001$ \\
\hline \multicolumn{6}{|l|}{ Gender: } \\
\hline Women & 77 & 72.6 & 63 & 61.2 & $\mathrm{p}=0.077$ \\
\hline Men & 29 & 27.4 & 40 & 38.8 & \\
\hline Assisted housing (years) $(\mathrm{M} \pm \mathrm{SD})$ & 5.5 & 4.6 & 3.8 & 3.4 & $\mathrm{p}=0.006$ \\
\hline \multicolumn{6}{|l|}{ Accommodation: } \\
\hline Unchanged & 72 & 100.0 & 99 & 97.1 & $\mathrm{p}=0.268$ \\
\hline Changed & 0 & 0.0 & 3 & 2.9 & \\
\hline \multicolumn{6}{|l|}{ Chronic illnesses: } \\
\hline Yes & 102 & 96.2 & 98 & 95.1 & $\mathrm{p}=0.746$ \\
\hline None & 4 & 3.8 & 5 & 4.9 & \\
\hline \multicolumn{6}{|l|}{ Number of chronic ailments: } \\
\hline None & 4 & 3.8 & 5 & 4.9 & $\mathrm{p}=0.016$ \\
\hline One & 3 & 2.8 & 6 & 5.9 & \\
\hline Two-three & 31 & 29.2 & 48 & 47.1 & \\
\hline Four or more & 68 & 64.2 & 43 & 42.2 & \\
\hline \multicolumn{6}{|l|}{ Vitamin B12 deficiency: } \\
\hline Yes & 13 & 12.3 & 2 & 1.9 & $\mathrm{p}=0.006$ \\
\hline No & 93 & 87.8 & 101 & 98.1 & \\
\hline \multicolumn{6}{|l|}{ Pernicious anemia: } \\
\hline Yes & 3 & 2.8 & 4 & 3.9 & $\mathrm{p}=0.719$ \\
\hline No & 103 & 97.2 & 99 & 96.1 & \\
\hline \multicolumn{6}{|l|}{ Iron-deficiency anemia: } \\
\hline Yes & 9 & 8.5 & 5 & 4.9 & $\mathrm{p}=0.408$ \\
\hline No & 97 & 91.5 & 98 & 95.1 & \\
\hline \multicolumn{6}{|l|}{ Osteoporosis: } \\
\hline Yes & 21 & 19.8 & 6 & 5.8 & $\mathrm{p}=0.002$ \\
\hline No & 85 & 80.2 & 97 & 94.2 & \\
\hline \multicolumn{6}{|l|}{ Bone fractures (traumatic): } \\
\hline Yes & 20 & 18.9 & 26 & 25.2 & $\mathrm{p}=0.266$ \\
\hline No & 86 & 81.1 & 77 & 74.8 & \\
\hline \multicolumn{6}{|l|}{ Polyneuropathy: } \\
\hline Yes & 4 & 3.8 & 5 & 4.9 & $\mathrm{p}=0.747$ \\
\hline No & 102 & 96.2 & 98 & 95.1 & \\
\hline \multicolumn{6}{|l|}{ Dementia (various types): } \\
\hline Yes & 11 & 10.4 & 16 & 15.5 & $\mathrm{p}=0.306$ \\
\hline No & 95 & 89.6 & 87 & 84.5 & \\
\hline \multicolumn{6}{|l|}{ Alzheimer's disease: } \\
\hline Yes & 12 & 11.3 & 1 & 1.0 & $\mathrm{p}=0.003$ \\
\hline No & 94 & 88.7 & 102 & 99.0 & \\
\hline \multicolumn{6}{|l|}{ Diabetes Mellitus (type I or II): } \\
\hline Yes & 21 & 19.8 & 11 & 10.7 & $\mathrm{p}=0.084$ \\
\hline No & 85 & 80.2 & 92 & 89.3 & \\
\hline \multicolumn{6}{|c|}{ Thyroid insufficiency (AI thyreoiditis): } \\
\hline Yes & 9 & 8.5 & 3 & 2.9 & $\mathrm{p}=0.135$ \\
\hline No & 97 & 91.5 & 100 & 97.1 & \\
\hline \multicolumn{6}{|l|}{ Rheumatoid arthritis: } \\
\hline Yes & 2 & 1.9 & 6 & 5.8 & $\mathrm{p}=0.142$ \\
\hline No & 104 & 98.1 & 97 & 94.2 & \\
\hline
\end{tabular}


Table 1 (continued)

Key demographic characteristics and disease history of the study subjects

\begin{tabular}{|c|c|c|c|c|c|}
\hline \multirow[t]{3}{*}{ Variable } & \multicolumn{4}{|c|}{ Study Site } & \multirow{3}{*}{$\begin{array}{c}\text { Significance } \\
\text { p-value }\end{array}$} \\
\hline & \multicolumn{2}{|c|}{ Tampere (Finland) } & \multicolumn{2}{|c|}{ Tartu (Estonia) } & \\
\hline & Number & Per Cent & Number & Per Cent & \\
\hline \multicolumn{6}{|l|}{ Celiac Disease (CD): } \\
\hline Yes & 3 & 2.8 & 0 & 0.0 & $\mathrm{p}=0.247$ \\
\hline No & 103 & 97.2 & 103 & 100.0 & \\
\hline \multicolumn{6}{|l|}{ Renal disease (not specified): } \\
\hline Yes & 12 & 11.3 & 5 & 4.9 & $\mathrm{p}=0.128$ \\
\hline No & 94 & 88.7 & 98 & 95.1 & \\
\hline \multicolumn{6}{|l|}{ Regular medication: } \\
\hline No regular medication & 6 & 5.7 & 11 & 10.7 & $\mathrm{p}=0.0001$ \\
\hline One drug & 5 & 4.7 & 12 & 11.7 & \\
\hline Two-three drugs & 12 & 11.3 & 34 & 33.0 & \\
\hline Four-five drugs & 27 & 25.5 & 25 & 24.3 & \\
\hline Six or more drugs & 56 & 52.8 & 21 & 20.4 & \\
\hline \multicolumn{6}{|l|}{ Alcohol consumption: } \\
\hline No use & 64 & 60.4 & 55 & 53.4 & $\mathrm{p}=0.002$ \\
\hline Social use & 38 & 35.8 & 40 & 38.8 & \\
\hline Daily use & 4 & 3.8 & 0 & 0.0 & \\
\hline Excess use (self-estimate) & 0 & 0.0 & 8 & 7.8 & \\
\hline \multicolumn{6}{|l|}{ Smoking history: } \\
\hline Never smoker & 87 & 82.1 & 71 & 68.9 & $\mathrm{p}=0.0001$ \\
\hline Previous smoker & 19 & 17.9 & 17 & 16.5 & \\
\hline Current smoker & 0 & 0.0 & 15 & 14.6 & \\
\hline Pack years smoked $(\mathrm{M} \pm \mathrm{SD})$ : & 20.6 & 21.0 & 22.0 & 13.1 & $\mathrm{p}=0.800$ \\
\hline
\end{tabular}

\section{Statistical analysis}

All statistical analyses were performed using IBM SPSS Statistics for Windows, version 23.0.0.2 (IBM, New York, USA) software. Frequency tables were analyzed using the Chi-square test, with the likelihood ratio (LR) or Fisher' $s$ exact test for categorical variables. Differences in the means of continuous variables were assessed using nonparametric Mann-Whitney or Kruskal-Wallis tests for 2- and multiple independent samples, respectively. All statistical tests were two-sided and declared significant at a p-value of $<0.05$.

\section{Results}

Table 1 compares the key demographic characteristics and medical history between the cohorts in Tampere and Tartu. In addition to being older in the Tampere cohort (mean age 84.2 years) than in Tartu (mean age $79.7)(p=0.0001)$, the subjects in the former also had spent a longer time in assisted-housing facility $(p=0.006)$, had more co-morbidities ( $>4$ diagnosed chronic illnesses) $(\mathrm{p}=0.016)$, previously diagnosed B12-vitamin deficiency $(p=0.006)$, osteoporosis $(p=0.002)$, Alzheimer's disease $(p=0.003)$, using regular medications more often $(p=0.0001)$, but instead had less alcohol consumption
( $p=0.002)$, and less likely to be ever or current smokers $(\mathrm{p}=0.0001)$.

The data collected for GastroPanel test are markedly different in the two cohorts (Table 2). None of the subjects in Tartu had HP eradication been performed as compared to $19.4 \%$ of those in Tampere $(p=0.0001)$. PPI use was significantly more rare in Tartu than in Tampere, as was the use of NSAIDs, antibiotics, B12vitamin supplementation, and previous gastroscopy (all; $\mathrm{p}=0.0001$ ).

The mean levels of the GastroPanel biomarkers and vitamin-B12 are summarized in Table 3. The levels of all but PGI were significantly different in Tampere and Tartu $(\mathrm{p}=0.0001)$. Consonant with more frequent HP infection in Tartu than in Tampere ( $52.4 \%$ vs. $25.4 \%$ ), PGII (marker of inflammation) and HP Ab levels were higher in Tartu. PGI/PGII ratio was lower but G-17 was higher in Tartu, both reflecting the prevalence of AGC.

There was a major difference in vitamin-B12 levels between Tampere and Tartu: 92.2 and $51.7 \mathrm{pmol} / 1$, respectively. Using the 3 -tier grading of the $\mathrm{B} 12$ vitamin levels, only $3.8 \%$ of the subjects in Tampere had values indicating deficiency ( $\geq 21-29 \mathrm{pmol} / \mathrm{l})$ and none had severe deficiency. The respective proportions in Tartu were $15.2 \%$ and $8.1 \%$ ( $\mathrm{p}=0.0001)$.

The distribution of the 5 diagnostic categories of the GastroPanel testing was significantly different in the two 
Table 2

Pertinent anamnestic data for the GastroPanel (GP) testing in Tampere and Tartu

\begin{tabular}{|c|c|c|c|c|c|}
\hline \multirow[t]{3}{*}{ Variable } & \multicolumn{3}{|c|}{ Study Site } & & \multirow{3}{*}{$\begin{array}{c}\text { Significance } \\
\text { p-value }\end{array}$} \\
\hline & \multicolumn{2}{|c|}{ Tampere (Finland) } & \multicolumn{2}{|c|}{ Tartu (Estonia) } & \\
\hline & Number & Per Cent & Number & Per Cent & \\
\hline \multicolumn{6}{|c|}{ GastroPanel test performed before: } \\
\hline Yes & 0 & 0.0 & 0 & 0.0 & NA \\
\hline No & 106 & 100.0 & 103 & 100.0 & \\
\hline \multicolumn{6}{|c|}{ Helicobacter pylori eradicated: } \\
\hline Yes & 18 & 19.4 & 0 & 0.0 & $\mathrm{p}=0.0001$ \\
\hline Never & 88 & 80.6 & 103 & 100.0 & \\
\hline \multicolumn{6}{|l|}{ Time since HP eradication: } \\
\hline Never & 88 & 83.0 & 103 & 100.0 & $\mathrm{p}=0.0001$ \\
\hline Less than 1 year & 16 & 15.1 & 0 & 0.0 & \\
\hline More than 1 year & 2 & 1.9 & 0 & 0.0 & \\
\hline \multicolumn{6}{|l|}{ PPI medication: } \\
\hline Not using & 57 & 55.3 & 76 & 74.5 & $\mathrm{p}=0.0001$ \\
\hline Using occasionally & 19 & 18.4 & 2 & 2.9 & \\
\hline Regular use & 27 & 26.2 & 23 & 22.5 & \\
\hline \multicolumn{6}{|l|}{ Symptoms of GERD: } \\
\hline No & 66 & 64.7 & 79 & 76.7 & $\mathrm{p}=0.067$ \\
\hline Yes, regularly & 36 & 35.3 & 24 & 23.3 & \\
\hline \multicolumn{6}{|l|}{ Use of NSAIDs: } \\
\hline Not using & 58 & 56.3 & 84 & 81.6 & $\mathrm{p}=0.0001$ \\
\hline Using regularly & 45 & 43.7 & 19 & 18.4 & \\
\hline \multicolumn{6}{|c|}{ Timing of most recent antibiotic use: } \\
\hline No recent use & 11 & 11.5 & 79 & 77.5 & $\mathrm{p}=0.0001$ \\
\hline Less than 1 year ago & 37 & 38.5 & 10 & 9.8 & \\
\hline More than 1 year ago & 48 & 50.0 & 13 & 12.7 & \\
\hline \multicolumn{6}{|l|}{ Vitamin-B *supplementation: } \\
\hline Yes & 54 & 50.9 & 4 & 3.9 & $\mathrm{p}=0.0001$ \\
\hline No & 52 & 49.1 & 99 & 96.1 & \\
\hline \multicolumn{6}{|l|}{ Ever performed gastroscopy: } \\
\hline Yes & 68 & 68.7 & 13 & 12.6 & $\mathrm{p}=0.0001$ \\
\hline No & 31 & 31.3 & 90 & 87.4 & \\
\hline
\end{tabular}

* Includes regular use of vitamin-B12 as part of multivitamin preparations;

cohorts (Table 4). This was particularly attributed to the higher proportion of HP-associated superficial gastritis ( $44.7 \%$ vs. $16.0 \%)$ and $\mathrm{AG}$ of the corpus $(14.6 \%$ and $9.5 \%)$ in Tartu, resulting in significantly lower prevalence $(39.8 \%)$ of the healthy stomach category in Tartu than in Tampere $(71.7 \%)$.

Table 5 depicts the B12-vitamin levels stratified by the 5 diagnostic categories of GastroPanel. B12 vitamin levels did not significantly vary between the 5 diagnostic categories, either in Tampere $(\mathrm{p}=0.915)$ or in Tartu $(\mathrm{p}=0.403)$, albeit markedly lower in the latter.
The risk of potential AG-related sequels (confirmed diagnoses) to associate with the manifest AG diagnosed by GastroPanel is estimated in Table 6. Of all these conditions diagnosed before the study, only two are significantly associated with the established AG: i) vitamin-B12 deficiency $(\mathrm{OR}=3.5)$, and ii) pernicious anaemia $(\mathrm{OR}=9.4)$.

\section{Discussion}

The present study evaluated the prevalence of co-morbidity potentially ascribed to vitamin-B12 
Table 3

Results of GastroPanel (GP) testing and Vitamin-B12 levels in Tampere and Tartu

\begin{tabular}{|c|c|c|c|c|c|}
\hline \multirow[t]{3}{*}{ Variable } & \multicolumn{4}{|c|}{ Study Site } & \multirow{3}{*}{$\begin{array}{c}{ }^{*} \text { Significance } \\
\text { p-value }\end{array}$} \\
\hline & \multicolumn{2}{|c|}{ Tampere (Finland) } & \multicolumn{2}{|c|}{ Tartu (Estonia) } & \\
\hline & Mean & $95 \% \mathrm{CI}$ & Mean & $95 \% \mathrm{CI}$ & \\
\hline \multicolumn{6}{|l|}{ GastroPanel Biomarker levels: } \\
\hline Pepsinogen I & 114.2 & $102.8-125.4$ & 107.0 & $90.9-123.0$ & $\mathrm{p}=0.468$ \\
\hline Pepsinogen II & 12.2 & 10.9-13.4 & 20.9 & $17.7-24.0$ & $\mathrm{p}=0.0001$ \\
\hline PGI/PGII ratio & 9.9 & 9.1-10.7 & 6.3 & 5.1-7.6 & $\mathrm{P}=0.0001$ \\
\hline Gastrin-17 & 5.5 & $3.4-7.6$ & 15.9 & $12.7-18.9$ & $\mathrm{p}=0.0001$ \\
\hline $\mathrm{HpAb}$ & 30.3 & $24.4-36.2$ & 232.2 & $177.5-286.9$ & $\mathrm{p}=0.0001$ \\
\hline \multicolumn{6}{|l|}{ Vitamin-B12 measurement: } \\
\hline Vitamin-B12 level (pmol/1) & 92.2 & 85.9-98.4 & 51.7 & $46.4-57.0$ & $\mathrm{p}=0.0001$ \\
\hline Vitamin-B12 graded: & Number & Per Cent & Number & Per cent & ${ }^{* *}$ Significance \\
\hline Normal (30-123) & 102 & 96.2 & 76 & 76.8 & $\mathrm{p}=0.0001$ \\
\hline Deficiency ( $\geq 21-29)$ & 4 & 3.8 & 15 & 15.2 & \\
\hline Severe deficiency $(<21)$ & 0 & 0.0 & 8 & 8.1 & \\
\hline
\end{tabular}

${ }^{*}$ ANOVA test; ${ }^{* *}$ Chi-Square (Fisher's exact) test.

Table 4

The GastroPanel (GP) test results in Tampere and Tartu

\begin{tabular}{|c|c|c|c|c|c|}
\hline \multirow[t]{3}{*}{ Variable } & \multicolumn{4}{|c|}{ Study Site } & \multirow{3}{*}{$\begin{array}{l}\text { Significance } \\
\text { p-value }\end{array}$} \\
\hline & \multicolumn{2}{|c|}{ Tampere (Finland) } & \multicolumn{2}{|c|}{ Tartu (Estonia) } & \\
\hline & Number & Per Cent & Number & Per Cent & \\
\hline \multicolumn{6}{|l|}{ GastroPanel diagnostic categories*: } \\
\hline Normal stomach mucosa & 76 & 71.7 & 41 & 39.8 & \multirow{5}{*}{$\mathrm{p}=0.0001$} \\
\hline${ }^{* *} \mathrm{HP}$-associated superficial gastritis & 17 & 16.0 & 46 & 44.7 & \\
\hline$* * * A G$ of the antrum & 3 & 2.8 & 0 & 0.0 & \\
\hline AG of the corpus & 10 & 9.5 & 15 & 14.6 & \\
\hline AG of the antrum and corpus (pangastritis) & 0 & 0.0 & 1 & 1.0 & \\
\hline
\end{tabular}

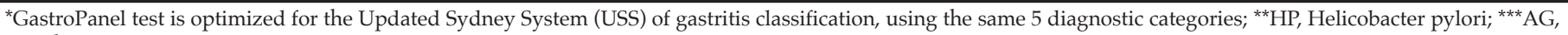
atrophic gastritis

deficiency as well as that of its most frequent cause, atrophic gastritis (AG), among elderly people in two different countries (Finland and Estonia) in the same geographic (Baltic) region. Given that these two countries are closely related in many respects, including geography, ethnicity and linguistic relatedness, the working hypothesis was that no major differences are to be expected between these two cohorts. The results, however, revealed several differences in the morbid history and laboratory test results between the two study cohorts that, in many parts, were unexpectedly striking (Table 1).

Due to the complexity of the medical history recorded in the study, it is unlikely to find a common denominator explaining all these observed differences, but the reasons must be multiple. One must consider that inhabitants of these two neighbouring countries have experienced a dramatically different recent history during the past 75 years since WW II, spanning the majority of their lifetime and certainly not without a profound impact on the divergent public health conditions is Estonia and Finland (31). Although independent for the past 25 years by now,
Estonia still bears the burden of the former Soviet Union reflected in the general health of the older generations born between 1916 and 1940, being enriched in this study cohort.

One of the leading hypothesis prompting this study is based on proposal that a substantial proportion of degenerative diseases encountered in old people can be traced back to deficiency of vitamin-B12 due to AGCassociated malabsorption (13-16). As to the medical history of the two cohorts (Table 1), B12-vitamin deficiency had been diagnosed much more rarely in Tartu than in Tampere $(p=0.006)$. Most likely, this is simply the question of the different diagnostic practices between the two countries, B12-vitamin measurement being more common in Finland than in Estonia. This is in alignment with the recorded frequency of vitamin B12 substitution in these two cohorts, being very rare $(3.9 \%)$ in Tartu but a common practice $(50.9 \%)$ in Tampere $(\mathrm{p}=0.0001)$ (Table 2$)$. As a direct consequence of neglected systematic controls, B12-vitamin levels in the current measurement were significantly lower in Tartu than in Tampere $(p=0.0001)$ 
Table 5

Vitamin-B12 levels related to GastroPanel (GP) diagnoses in Tampere and Tartu

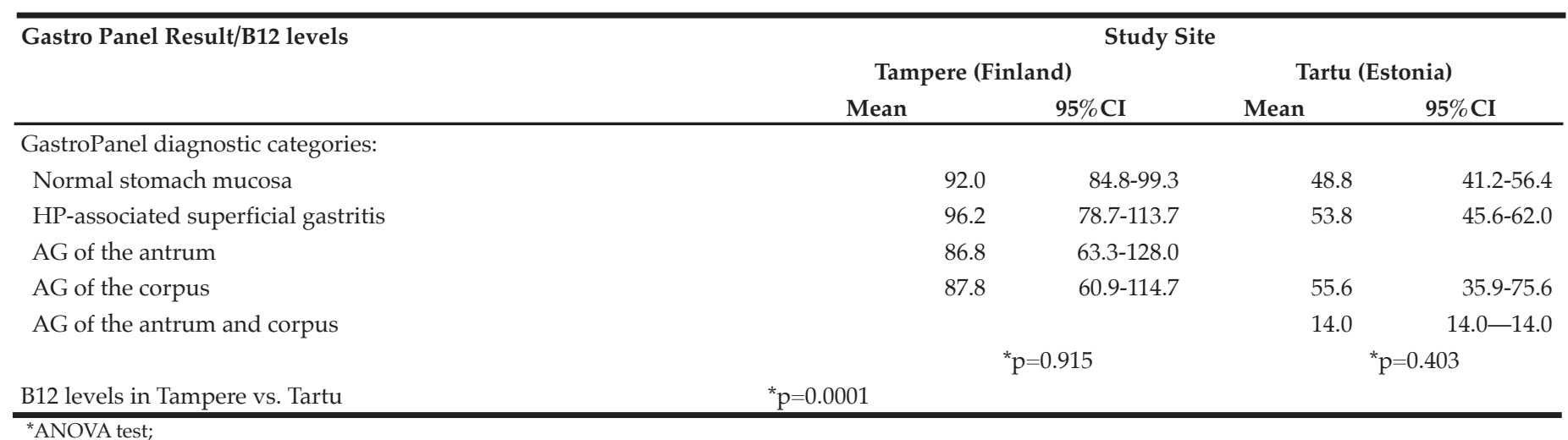

(Table 3).

The development of B12 vitamin deficiency as a result of AG is a slow process, and the clinical manifestations are often delayed until advanced age (15). It has been estimated that there are nearly $15,000(0.28 \%)$ people in Finland who suffer from vitamin-B12 deficiency $(13,14)$. As related to the figures established in the two cohorts for the previously diagnosed (Table 1) and current vitamin-B12 deficiency (Table 3), these data implicate that B12 vitamin deficiency is enriched in the elderly population. The importance of early diagnosis of B12 vitamin deficiency cannot be overemphasized (15). This is because peripheral neuropathy, depression and dementia begin to develop even before pernicious-type anaemia becomes detectable, and can cause permanent damage if not adequately treated (13, 14, 15, 16). Accordingly, instead of using B12 vitamin tests that detect manifest B12 vitamin deficiency, it would be very important to use tests that predict the risk of B12 vitamin deficiency years before the manifest symptoms. Such a predictive means is offered by GastroPanel test, accurately detecting AGC patients who are at high risk for developing vitamin-B12 malabsorption within a few years $(21,22,23,24,25,26,27$, 28).

Targeted GastroPanel screening is recommended (17) for special groups of patients at significantly increased risk of $\operatorname{AG}(17,29)$. Such high-risk groups include: a) autoimmune thyroiditis, b) type 1 diabetes, c) coeliac disease, and d) rheumatoid arthritis. As already insinuated, also Alzheimer's disease (AD) (and other dementia) could be included in this list, while linked to vitamin-B12 deficiency (30), and potentially predictable years earlier by testing for AG. For this very same reason, we were also interested in the prevalence of irondeficiency anaemia and osteoporosis, both attributable to AG because of malabsorption of iron and calcium $(13,14,29)$. More than of their simple prevalence in the two cohorts (Table 1) we were interested to assess, whether any of these conditions can be predicted by the AG diagnosed by GastroPanel.

The study subjects were stratified according to their
GastroPanel results into two groups: 1) those with AG (any part of stomach), and 2) those with no AG (Table 6). Altogether, $29 / 209(13.8 \%)$ subjects were classified as AG: $12 . \%$ in Tampere and $15.6 \%$ in Tartu (Table 4). This unexpectedly small difference between the two countries is explained by two counteracting factors: i) the significantly higher frequency of HP-infection in Estonia $(52.4 \%$ vs. $25.4 \%)$, well known from previous reports $(32,33,34)$, and ii) the significantly lower age of the study subjects in Tartu. This corroborates the data from 4,256 Finnish volunteers, reporting $8 \%$ prevalence of moderate to severe AG among 70+ year-old. Quite unexpectedly, $13 \%$ of these people used regular PPI medication (2). For reference, regular or irregular use of PPI among AG patients in the present cohort was $14.3 \%(4 / 28)$, being markedly less than among non-AG subjects $(38.4 \%)$, but equally irrational as previously discussed (2).

Of the disease conditions attributed to $\operatorname{AG}(13,14,15,30)$, the following had an OR near 1.0 to associate with AG: osteoporosis, bone fractures, polyneuropathy, and rheumatoid arthritis. AG was less common among subjects with dementia, AD, DM, IBD and CD, as compared with non-diseased subjects. Among subjects with autoimmune thyreoiditis, however, AG was almost twice as common as in those with no thyreoiditis $(25.0 \%$ and $13.2 \%)(\mathrm{OR}=2.19)$, but the difference did not reach statistical significance. Of all recorded conditions, only two were significantly associated with AG: 1) previously diagnosed B12 vitamin deficiency, and 2) previously diagnosed pernicious anaemia (Table 6). The failure of vitamin-B12 deficiency detected in the current testing (Table 5) to associate with AG is explained by the fact that practically all previously diagnosed cases were receiving adequate supplementation.

Taken together, vitamin-B12 deficiency (diagnosed before and current) was more common in Estonia (24.3\%) than in Finland $(16.0 \%)(p=0.137)$. These figures are not far away from the estimates that as many as $20 \%$ of retired people suffer from active vitamin B12 deficiency (15). However, the main difference between the two countries is the fact that the vast majority $(23 / 25 ; 92 \%)$ 
Table 6

The risk of potential sequels of atrophic gastritis stratified by GastroPanel status

\begin{tabular}{|c|c|c|c|c|c|c|}
\hline \multirow[t]{3}{*}{ Variable } & \multicolumn{3}{|c|}{ Gastric Mucosal Status in GastroPanel* } & & \multirow{3}{*}{$\begin{array}{c}\text { Risk Estimate } \\
\text { OR }(95 \% \text { CI })\end{array}$} & \multirow{3}{*}{$\begin{array}{c}\text { Significance } \\
\text { p-value }\end{array}$} \\
\hline & \multicolumn{2}{|c|}{ Atrophic Gastritis } & \multicolumn{2}{|c|}{ No atrophy } & & \\
\hline & Number & Per Cent & Number & Per Cent & & \\
\hline \multicolumn{7}{|l|}{ Gender: } \\
\hline Women & 20 & 14.3 & 120 & 85.7 & $1.1(0.47-2.58)$ & 0.806 \\
\hline Men & 9 & 13.0 & 60 & 87.0 & & \\
\hline \multicolumn{7}{|c|}{ Vitamin B12 deficiency: } \\
\hline Yes & 5 & 33.3 & 10 & 66.7 & $3.54(1.11-11.24)$ & 0.040 \\
\hline No & 24 & 12.4 & 170 & 87.7 & & \\
\hline \multicolumn{7}{|l|}{ Pernicious anemia: } \\
\hline Yes & 4 & 57.1 & 3 & 42.9 & $9.44(1.99-44.67)$ & 0.008 \\
\hline No & 25 & 12.4 & 177 & 87.6 & & \\
\hline \multicolumn{7}{|c|}{ Iron-deficiency anemia: } \\
\hline Yes & 1 & 7.1 & 13 & 92.9 & $0.45(0.09-3.64)$ & 0.698 \\
\hline No & 28 & 14.4 & 167 & 85.6 & & \\
\hline \multicolumn{7}{|l|}{ Osteoporosis: } \\
\hline Yes & 4 & 14.8 & 23 & 85.2 & $1.09(0.34-3.42)$ & 0.774 \\
\hline No & 25 & 13.7 & 157 & 86.3 & & \\
\hline \multicolumn{7}{|c|}{ Bone fractures (traumatic): } \\
\hline Yes & 6 & 13.0 & 40 & 87.0 & $0.91(0.34-2.39)$ & 0.852 \\
\hline No & 23 & 14.1 & 140 & 85.9 & & \\
\hline \multicolumn{7}{|l|}{ Polyneuropathy: } \\
\hline Yes & 1 & 11.1 & 8 & 88.9 & $0.76(0.09-6.38)$ & 0.801 \\
\hline No & 28 & 14.0 & 172 & 86.0 & & \\
\hline \multicolumn{7}{|c|}{ Dementia (various types): } \\
\hline Yes & 2 & 7.4 & 25 & 92.6 & $0.45(0.10-2.05)$ & 0.385 \\
\hline No & 27 & 14.8 & 155 & 85.2 & & \\
\hline \multicolumn{7}{|c|}{ Alzheimer's disease: } \\
\hline Yes & 0 & 0.0 & 13 & 100.0 & NA & 0.222 \\
\hline No & 29 & 14.8 & 167 & 85.2 & & \\
\hline \multicolumn{7}{|c|}{ Diabetes Mellitus (type I or II): } \\
\hline Yes & 1 & 3.1 & 31 & 96.9 & $0.17(0.02-1.30)$ & 0.056 \\
\hline No & 28 & 15.8 & 149 & 84.2 & & \\
\hline \multicolumn{7}{|c|}{ Thyroid insufficiency (AI thyreoiditis): } \\
\hline Yes & 3 & 25.0 & 9 & 75.0 & $2.19(0.55-8.62)$ & 0.222 \\
\hline No & 26 & 13.2 & 171 & 86.8 & & \\
\hline \multicolumn{7}{|c|}{ Rheumatoid arthritis: } \\
\hline Yes & 2 & 10.0 & 18 & 90.0 & $0.66(0.14-3.03)$ & 0.747 \\
\hline No & 27 & 14.3 & 162 & 85.7 & & \\
\hline \multicolumn{7}{|c|}{ Inflammatory bowel disease (IBD): } \\
\hline Yes & 0 & 0.0 & 5 & 100.0 & NA & 0.613 \\
\hline No & 29 & 14.2 & 175 & 85.8 & & \\
\hline \multicolumn{7}{|l|}{ Celiac Disease (CD): } \\
\hline Yes & 0 & 0.0 & 3 & 100.0 & NA & 0.688 \\
\hline No & 29 & 14.1 & 177 & 85.9 & & \\
\hline
\end{tabular}

*All cases suggesting atrophic gastritis in GastroPanel testing; NA, not applicable

of these cases have remained undiagnosed in Estonia, which is in sharp contrast to Finland, where only $4 / 17$ $(23.5 \%)$ presented with mild B12 deficiency in the current testing, the rest having been diagnosed before (Table 3). The present results also confirm the well-established association of AG with vitamin-B12 deficiency and pernicious anaemia. In fact, of all known or implicated sequels of $A G$, these two were the only ones convincingly linked with the AG diagnosis in the present study (Table 6 ). The failure to link any of the (rare) neurological 
complications with AG is likely explained by the adequate supplementation of all diagnosed deficiency cases. Most likely, the same is true with iron-deficiency anaemia and osteoporosis, albeit the supplementation was not recorded in this study. As to the other conditions known to be associated with an increased risk of AG (DM, RA, IBD, CD, AI-thyreoiditis), these were far too few to enable any firm conclusions,.

To conclude, this study emphasizes the importance of an early diagnosis of vitamin-B12 deficiency in elderly people, and adequate supplementation of all detected cases. This is best done by using targeted screening by GastroPanel, detecting the subjects at risk, i.e., those with any degree of $A G$, even years before the development of protean clinical manifestations of B12 deficiency. This, if anything, is a solid example how an appropriate implementation of the primary prevention (risk group screening) can have a major impact in the quality of life during the later years of life.

Acknowledgements: The skilful technical assistance of Ms Tia Länsipuro is gratefully acknowledged, who took care of the blood samplings of all study subjects in Tampere and Tartu.

Conflict of interest: R. Aine, E. Kahar, K. Aitokari and A. Peetsalu have nothing to disclose. C. Eklund, J. Salminen, K. Syrjänen, and L. Paloheimo are employees of Biohit Oyj.

\section{Ethical standard: Declaration of Helsinki.}

\section{References}

1. Varis K, Isokoski M. Screening of type A gastritis. Ann Clin Res 1981;13:133-8.

2. Telaranta-Keerie A, Kara R, Paloheimo L, Härkönen M, Sipponen P. Prevalence of undiagnosed advanced atrophic corpus gastritis in Finland: an observational study among 4,256 volunteers without specific complaints. Scand J Gastroenterol 2010;45:1036-1041.

3. Sipponen P, Graham D. Importance of atrophic gastritis in diagnostics and prevention of gastric cancer: application of plasma biomarkers. Scand J Gastroenterol 2007;42:2-10.

4. Malfertheiner P, Sipponen P, Naumann M ym. Lejondal H. pylori-Gastric Cancer Task Force. Helicobacter pylori eradication has the potential to prevent gastric cancer: a state-of-the-art critique. Am J Gastroenterol 2005;100:2100-2115

5. Benberin V, Bektayeva R, Karabayeva R, Lebedev A, Akemeyeva K, Paloheimo L, Syrjänen K. Prevalence of H.pylori infection and atrophic gastritis among ymptomatic and dyspeptic adults in Kazakhstan. A Hospital-Based screening with a panel of serum biomarkers. Anticancer Res 2013;33:4595-4602

6. International Agency for Research on Cancer, World Health Organization Schistosomes, liver flukes and Helicobacter pylori. IARC working group on the evaluation of carcinogenic risks to human. Monogr Eval Carcinog Risks Hum 1994;61:218-220.

7. Correa P, Haenszel W, Cuello C, Zavala D, Fontham E, Zarama G, et al Gastric precancerous process in a high risk population: cohort follow-up. Cancer Res 1990;50:4737-4740.

8. Filipe MI, Munoz N, Matko I, Kato I, Pompe-Kirn V, Jutersek A, et al Intestinal metaplasia types and the risk of gastric cancer: a cohort study in Slovenia. Int J Cancer 1994;57:324-329.

9. Uemura N, Okamoto S, Yamamoto S, Matsumura N, Yamaguchi S, Yamakido $\mathrm{M}$, et al. Helicobacter pylori infection and the development of gastric cancer. N Engl J Med 2001;345:829-832.

10. Sipponen P, Kekki M, Haapakoski J, Ihamäki T, Siurala M. Gastric cancer risk in chronic atrophic gastritis: statistical calculations of cross-sectional data. Int J Cancer 1985;35:173-177.

11. Ohata H, Kitauchi S, Yoshimura N, Mugitani K, Iwane M, Nakamura H, et al. Progression of chronic atrophic gastritis associated with Helicobacter pylori infection increases risk of gastric cancer. Int J Cancer 2004;109:138-143.

12. Varis K, Sipponen P, Laxen F, Samloff IM, Huttunen JK, Taylor PR, and The Helsinki Gastritis Study Group. Implications of serum pepsinogen I in early endoscopic diagnosis of gastric cancer and dysplasia. Scand J Gastroenterol
2000:35:950-956.

13. Sipponen P, Laxén F, Huotari K, Härkönen M. Prevalence of low vitamin B12 and high homocysteine in serum in an elderly male population: association with atrophic gastritis and Helicobacter pylori infection. Scand J Gastroenterol 2003;38:1209-1216

14. Sipponen P, Härkönen M. Hypochlorhydric stomach: a risk condition for calcium malabsorption and osteoporosis? Scand J Gastroenterol 2010:45;133138.

15. Stabler S. Vitamin B12 deficiency. N Engl J Med 2013;368:149-160

16. Bolander-Gouaille C. Focus on Homocysteine and the Vitamins involved in its Metabolism. Berlin: Springer Verlag. 2002.

17. Agréus L, Kuipers EJ, Kupcinskas L, Malfertheiner P, Di Mario F, Leja M, Mahachai V, Yaron N, van Oijen M, Perez Perez G, Rugge M, Ronkainen J, Salaspuro M, Sipponen P, Sugano K, Sung J. Rationale in diagnosis and screening of atrophic gastritis with stomach-specific plasma biomarkers. Scand J Gastroenterol 2012;47:136-147.

18. Storskrubb T, Aro P, Ronkainen J, Sipponen P, Nyhlin H, Talley NJ, et al Serum biomarkers provide an accurate method for diagnosis of atrophic gastritis in a general population: the Kalixanda study. Scand J Gastroenterol 2008;43:1448-55.

19. Vohlonen I, Syrjänen K, Karhu J. Serum biomarker-based screening of the risk groups of stomach cancer. Preliminary results of a feasibility study in Finland. Turkish J Acad Gastroenterol 2013;12:47-51.

20. Syrjänen KJ, Sipponen P, Härkönen M, Peetsalu A, Korpela S. Accuracy of GastroPanel testing in detection of atrophic gastritis. Eur J Gastroenterol Hepatol 2015;27:102-104.

21. Väänänen $H$, Vauhkonen $M$, Helske $T$, Kääriäinen I, rasmussen $M$, TunturiHihnala H, Koskenpato J, Sotka M, Turunen M, Sandström R, Ristinkankare M, Jussila A, Sipponen P. Non-endoscopic diagnosis of atrophic gastritis with a blood test. Correlation between gastric histology and serum levels of gastrin-17 and pepsinogen I: a multicentre study. Eur J Gastroenterol Hepatol 2003;15:885-891.

22. Hartleb M, Wandzel P, Waluga M, Matyszczyk B, Bołdys H, Romanczyk T. Non-endoscopic diagnosis of multifocal atrophic gastritis; efficacy of serum gastrin-17, pepsinogens and Helicobacter pylori antibodies. Acta Gastroenterol Belg 2004;67:320-326.

23. Pasechnikov VD, Chukov SZ, Kotelevets SM, Mostovov AN, Mernova VP, Polyakova MB. Invasive and non-invasive diagnosis of Helicobacter pyloriassociated atrophic gastritis: a comparative study. Scand J Gastroenterol 2005;40:297-301.

24. Germaná B, Di Mario F, Cavallaro LG, Moussa AM, Lecis P, Liatoupolou S, Comparato G, Carloni C, Bertiato G, Battiestel M, Papac N, Aragona G, Cavestro GM, Iori V, Merli R, Bertolini S, Caruana P, Franzé A. Clinical usefulness of serum pepsinogens I and II, gastrin-17 and anti-Helicobacter pylori antibodies in the management of dyspeptic patients in primary care. Digest Liver Dis 2005;37:501-508.

25. Valle MJ, Varasa TA, Pardo RL, Merlo RR, Pérez Grueso MJ, Escobedo RM, Torres MA, Boyd RC, Carrobles Jiménez JM. Diagnóstico serológico de gastritis atrófica con una combinación de pepsinógeno I y II, gastrina-17 y anticuerpos anti-Helicobacter pylori. Gastroenterol Hepatol 2007;30:567-571.

26. Storskrubb T, Aro P, Ronkainen J, Sipponen P, Nyhlin H, Talley NJ. Serum biomarkers provide an accurate method for diagnosis of atrophic gastritis in a general population: the Kalixanda study. Scand J Gastroenterol 2008;43:14481455.

27. Masci E, Pellicano R, Mangiavillano B, Luigiano C, Stelitano L, Morace C, Viale E, Freschi M, Locatelli M, Ieri R, Cavallaro A, Testoni S, Testoni PA. GastroPanel test for non-invasive diagnosis of atrophic gastritis in patients with dyspepsia. Minerva Gastroenterol Dietol 2014;60:79-83.

28. Kurilovich SA, Belkovets AV, Reshetnikov OV, Openko TG, Malyutina SK, Ragino YI, Scherbakova LV, Leja M, Paloheimo L, Syrjänen K, Voevoda MI Stomach-specific biomarkers (GastroPanel) can predict the development of gastric cancer in Caucasian population: A longitudinal nested case-control study in Siberia. Anticancer Res 2016;36:247-254.

29. Suovaniemi O. GastroPanel-tutkimus osaksi dyspepsian hoitokäytäntöä. Yleislääkäri 2007;4:104-106.

30. Refsum H. Smith AD. Low vitamin B12 status in confirmed Alzheimer's disease as revealed by serum holotranscobalamin. J Neurol Neurosurg Psychiatry 2003;74:959-961.

31. Strandberg TE, Saks K, Soots A, Pitkälä KH, Sintonen H, Huusko T, Tilvis RS Comparison of health and quality of life of urban elderly in an old and new EU country. Ceska Geriat Rev 2007;11:153-167.

32. Leja M, Cine E, Rudzite D, Vilkoite I, Huttunen T, Daugule I, RumbaRozenfelde I, Pimanov S, Liepniece-Karele I, Pahamova J, Purmalis K, Eglitis J, Pirags V, Dzerve V, Ergglis A. Prevalence of Helicobacter pylori infection and atrophic gastritis in Latvia. Eur J Gastreoenterol hepatol 2+012;24:14101417.

33. Oona M, Utt M, Nilsson I, Uibo O, Vorobjova T, Maaroos HI. Helicobacter pylori infection in children in Estonia: decreasing seroprevalence during the 11-year period of profound socioeconomic changes. Helicobacter 2004;9:233241.

34. Maaroos HI. Helicobacter pylori infection in Estonian population: is it a 